\title{
Time of highest tuberculosis death risk and associated factors: an observation of 12 years in Northern Thailand
}

This article was published in the following Dove Press journal:

International Journal of General Medicine

25 February 201I

Number of times this article has been viewed

\author{
Saiyud Moolphate ${ }^{1,2}$ \\ Myo Nyein Aung 1,3 \\ Oranuch Nampaisan' \\ Supalert Nedsuwan ${ }^{4}$ \\ Pacharee Kantipong ${ }^{5}$ \\ Narin Suriyon ${ }^{6}$ \\ Chamnarn \\ Hansudewechakul ${ }^{6}$ \\ Hideki Yanai ${ }^{7}$ \\ Norio Yamada ${ }^{2}$ \\ Nobukatsu Ishikawa ${ }^{2}$ \\ 'TB/HIV Research Foundation, Chiang \\ Rai, Thailand; ${ }^{2}$ Research Institute of \\ Tuberculosis, Japan \\ Anti-Tuberculosis Association \\ (RIT-JATA), Tokyo, Japan; \\ ${ }^{3}$ Department of Pharmacology, \\ University of Medicine, Mandalay, \\ Myanmar; ${ }^{4}$ Department of Preventive \\ and Social Medicine, Chiang Rai \\ Regional Hospital, Chiang Rai, \\ Thailand; ${ }^{5}$ Department of Health \\ Service System Development, Chiang \\ Rai Regional Hospital, Chiang Rai, \\ Thailand; ${ }^{6}$ Provincial Health Office, \\ Chiang Rai, Thailand; ' Department of \\ Clinical Laboratory, Fukujuji Hospital, \\ Tokyo, Japan
}

Correspondence: Myo Nyein Aung

TB/HIV Research Foundation,

I050 Sathanpayabarn Road,

Muang District, Chiang Rai,

Thailand 57000

Tel +66 53713135

Fax +66 53752448

or

Department of Pharmacology, University of Medicine, Mandalay, 30th street, block between 73rd and

74th streets, Chan Aye Thar Zan,

Mandalay, Myanmar 0507I

$\mathrm{Tel}+959534 \mid 453$

Email dr.myonyeinaung@gmail.com
Purpose: Northern Thailand is a tuberculosis (TB) endemic area with a high TB death rate. We aimed to establish the time of highest death risk during TB treatment, and to identify the risk factors taking place during that period of high risk.

Patients and methods: We explored the TB surveillance data of the Chiang Rai province, Northern Thailand, retrospectively for 12 years. A total of 19,174 TB patients (including 5,009 deaths) were investigated from 1997 to 2008, and the proportion of deaths in each month of TB treatment was compared. Furthermore, multiple logistic regression analysis was performed to identify the characteristics of patients who died in the first month of TB treatment. A total of 5,626 TB patients from 2005 to 2008 were included in this regression analysis.

Result: The numbers of deaths in the first month of TB treatment were $38 \%, 39 \%$, and $46 \%$ in the years 1997-2000, 2001-2004, and 2005-2008, respectively. The first month of TB treatment is the time of the maximum number of deaths. Moreover, advancing age, HIV infection, and being a Thai citizen were significant factors contributing to these earlier deaths in the course of TB treatment.

Conclusion: Our findings have pointed to the specific time period and patients at higher risk for TB death. These findings would be useful for prioritizing interventions in order to diminish TB-related deaths globally. Studies based on these findings are necessary for the introduction of newer intervention strategies.

Keywords: tuberculosis, TB death, Thailand, time of death

\section{Introduction}

Tuberculosis (TB) is still a worldwide deadly threat despite global and national control programs. Every year there are two million TB-related deaths globally. ${ }^{1}$ The global TB mortality rate was $29 / 100,000$ in 1990 and increased to peak at 32/100,000 in 2000 before decreasing to $27 / 100,000$ in $2007 .{ }^{2}$ After a decades-long battle against TB, the World Health Organization (WHO) has set the goal to reduce TB mortality below 15 per 100,000 by 2015 .

TB mortality rate is different in developing and developed countries. A Centers for Disease Control and Prevention surveillance report in 2008 showed that TB mortality in the United States was 0.2 per $100,000 .^{3}$ In contrast, Thailand, which was ranked 18 th of the top 22 highest TB-burdened countries, had a mortality rate of 21/100,000 in $2007 .{ }^{4}$ Furthermore, even with the low level of mortality, the proportion of pulmonary TB patients who died during treatment was reported to be highest in the WHO European region., ${ }^{2,5}$ The disease is still the cause of death for large numbers of people across the world.

In recent years, Thailand could not achieve the WHO target treatment success rate. One of the reasons for this is the high proportion of TB death on treatment: $11 \%$ in 2001 
and $9 \%$ in 2007 , which were the highest proportions in the WHO Southeast Asian region. These figures were very similar to the proportion of TB patients' deaths ( $8 \%$ ) reported by the European region, which was the highest among all WHO regions in $2007 .{ }^{5}$ Chiang Rai province, the study site of the current study, is a TB and HIV endemic area. It has a higher TB case fatality rate (17.1\%) than its neighboring provinces in Northern Thailand. ${ }^{6}$ Previous literature has stated that living in Chiang Rai province itself is a risk factor of death among TB patients (adjusted relative risk 2.7 ). ${ }^{7}$

TB is a chronic communicable disease that is curable. Moreover, TB death is preventable. To aid prevention, it is necessary to specify the time, place, and persons at higher risk of death. Identifying the time when most TB deaths occur during the course of treatment is necessary. Characteristics of patients who died ofTB during that high-risk period should be observed to specify social and clinical risk groups of TB death.

We aimed to find out the time of highest on-treatment death along the timeline of TB treatment. Furthermore, we tried to identify the characteristics of TB patients who died during that high-risk period.

\section{Material and methods Data collection and source}

TB surveillance data were used for the study. The study was approved by Chiang Rai Ethical Committee and Chiang Rai Provincial Health Office, Thailand. TB surveillance data covered 17 hospitals in Chiang Rai province.

\section{Study population}

The study population comprised TB patients selected based on the following criteria. These criteria were applied for both parts of the analysis.

\section{Inclusion criteria}

1. All TB cases treated and reported in Chiang Rai province, including new cases, relapse, treatment after failure, treatment after default, and others according to WHO criteria.

2. Pulmonary as well as extrapulmonary tuberculosis.

\section{Exclusion criteria}

1. Defaulted TB cases.

2. Transfer-in cases from other areas and transfer-out cases during treatment.

3. Patients less than 16 years of age.

The study contained two parts. In the first part of the study, TB surveillance data of the past 12 years were examined. All 5009 deaths among 19,174 TB patients from 1997 to 2008 were retrospectively studied.

Secondly, to analyze the factors associated with patients who died during the period of highest death, prospectively collected data were used. A total of 5,626 TB patients from 2005 to 2008 were included in the second part of the analysis. Populations in the first and second part of the analysis had the same criteria for inclusion and exclusion. Hypothesis-driven data collection was started in 2005 beyond the scope of routine surveillance. It was made successful because of the Thailand TB Active Surveillance Network (TB-Net). TB-Net was a collaboration of the Ministry of Public Health, Thailand, Bangkok Metropolitan Administration, the Research Institute of Tuberculosis, Japan, and the U.S. Centers for Disease Control and Prevention in five provinces of Thailand, including Chiang Rai. This analysis used the data collected by the RIT in Chiang Rai province.

\section{TB treatment}

TB patients in Chiang Rai province were treated according to National TB Program treatment guidelines. Choice of TB treatment regimen was based on the criteria of new case, retreatment, and drug resistance regimen according to the treatment category in the WHO guidelines. ${ }^{8}$

\section{Death}

Death from any cause during TB treatment was listed as on-treatment $\mathrm{TB}$ death according to the WHO TB treatment outcome definition. ${ }^{8}$ Death during TB treatment was confirmed by using hospital records and the death registry in the online national vital status database.

\section{Laboratory tests}

Microscopic examination of sputum samples for acid-fast bacilli by Ziehl-Neelsen stain was carried out in the mycobacterial laboratory of each hospital in Chiang Rai province. Bacteriological diagnosis of tuberculosis culture was done at the mycobacterial laboratory of the Chiang Rai provincial hospital. Throughout the study period, solid culture via Ogawa medium was used. After October 2005, automated liquid culture system Bactec ${ }^{\mathrm{TM}}$ Mycobacterial Growth Indicator Tube (MGIT 960 ${ }^{\mathrm{TM}}$ ) was used for TB culture. Drug susceptibility tests (DSTs) were carried out at the National TB Reference Laboratory, Bangkok, Thailand, by using the proportion method with a Lowenstein-Jensen medium before 2005. After 2005, identification and DSTs for isoniazid, rifampicin, ethambutol, and streptomycin were performed at the National TB Reference Laboratory using MGIT. Voluntary counseling and testing of HIV infection was 
offered to every TB patient. Consented cases were tested for HIV antibody.

\section{Statistical analysis}

Stata Version 11 was used to analyze the data. Of 5009 total deaths from 1997 to 2008, the number and proportion of deaths in each month of TB treatment were analyzed descriptively and shown graphically for every 4-year interval for 1997-2000, 2001-2004, and 2005-2008 (Figures 1A-1C).

A total of 5,009 deaths occurred among 19,174 reported TB patients within 12 years. The events of death were analyzed against the timeline of TB treatment using smooth hazard risk estimation. The probability of death in the timeline of TB treatment was extrapolated by Kernel smoothed hazard rates estimation curve (Figure 2).

Backward multilogistic regression analysis was performed to identify factors associated with the TB patients who died within the first month. Factors that contributed to 534 TB patients' deaths in the first month of treatment were investigated and compared with 5,092 survivors. Multiple logistic regression was restricted to variables with a $P$ value less than 0.1 in bivariate analysis. Gender, age, race, marital status, education, occupation, BCG scar, patient type based on treatment regimen, and HIV status were included in multilogistic regression. A $P$ value less than 0.05 was considered statistically significant, with a 95 percent confidence interval (CI) to determine adjusted odds ratio (aOR).

\section{Results}

\section{First part of the analysis}

Our observation showed that the largest number of TB patients died in the first month of TB treatment. Death rates in the first month were 38\% of all TB deaths in 1997-2000, $39 \%$ of all TB death in 2001-2004, and $46 \%$ of all TB death in 2005-2008 (Figures 1A, 1B, and 1C). The largest proportion of TB patients died in the first month of TB treatment in a constant pattern for 12 years.

The result of time-event analysis by Kernel smoothed hazard rates estimation curve revealed higher probability of TB death in the first month (Figure 2). The trend of TB deaths can be seen to decline over the timeline of TB treatment.

\section{Second part of the analysis}

Analysis of factors associated with TB deaths in the first month included $5626 \mathrm{~TB}$ patients. The basic characteristics of patients are shown in Table 1. The proportion of male patients was higher than female patients. More than $85 \%$
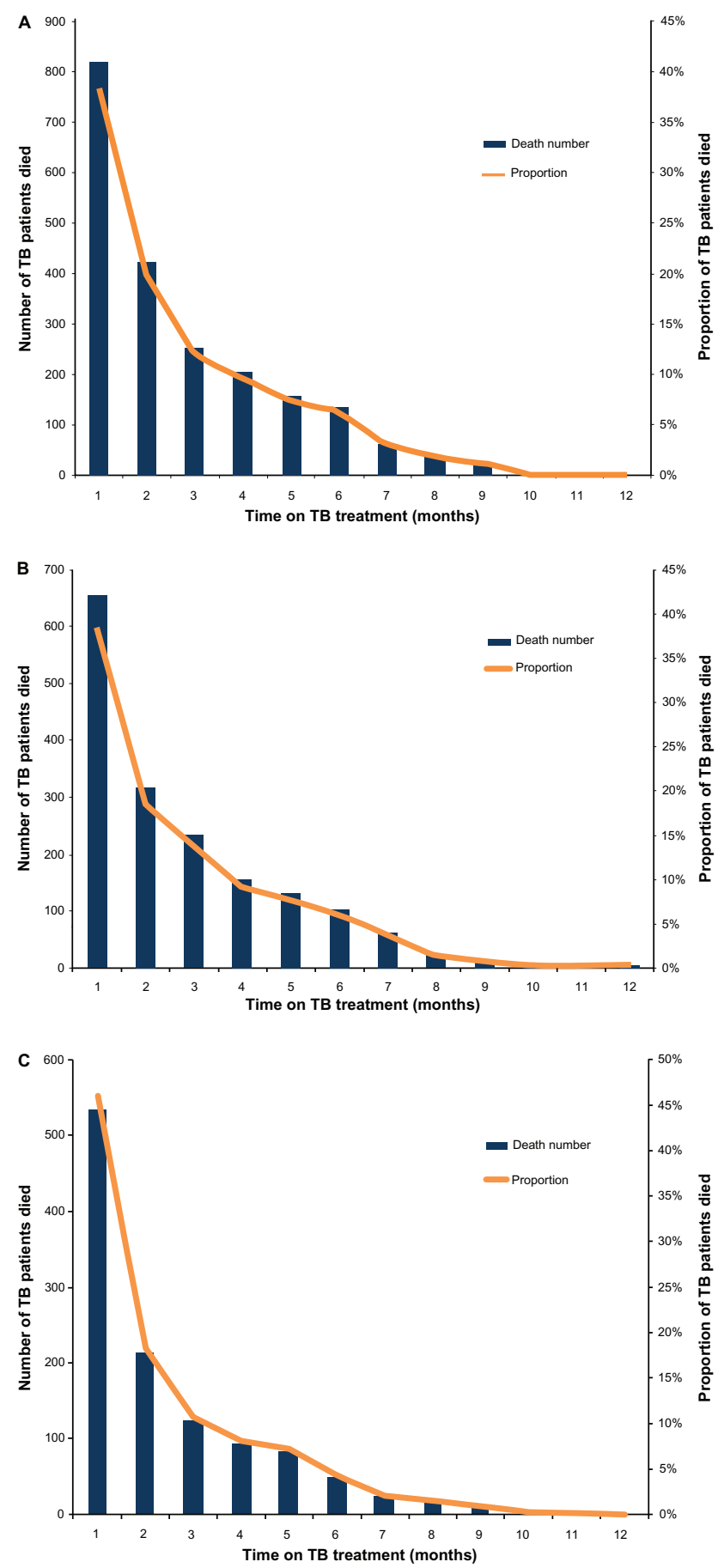

Figure I A) Deaths of TB patients in each month of TB treatment in Chiang Rai, Thailand (1997-2000). B) Deaths of TB patients in each month of TB treatment in Chiang Rai, Thailand (200I-2004). C) Deaths of TB patients in each month of TB treatment in Chiang Rai, Thailand (2005-2008).

of the patients were Thai, and more than a third were HIV infected.

The results of bivariate and multivariate analysis are shown in Table 2. Age group, HIV status, and being a Thai citizen were significant risk factors associated with death in the first month of TB treatment after adjustment by multivariate 


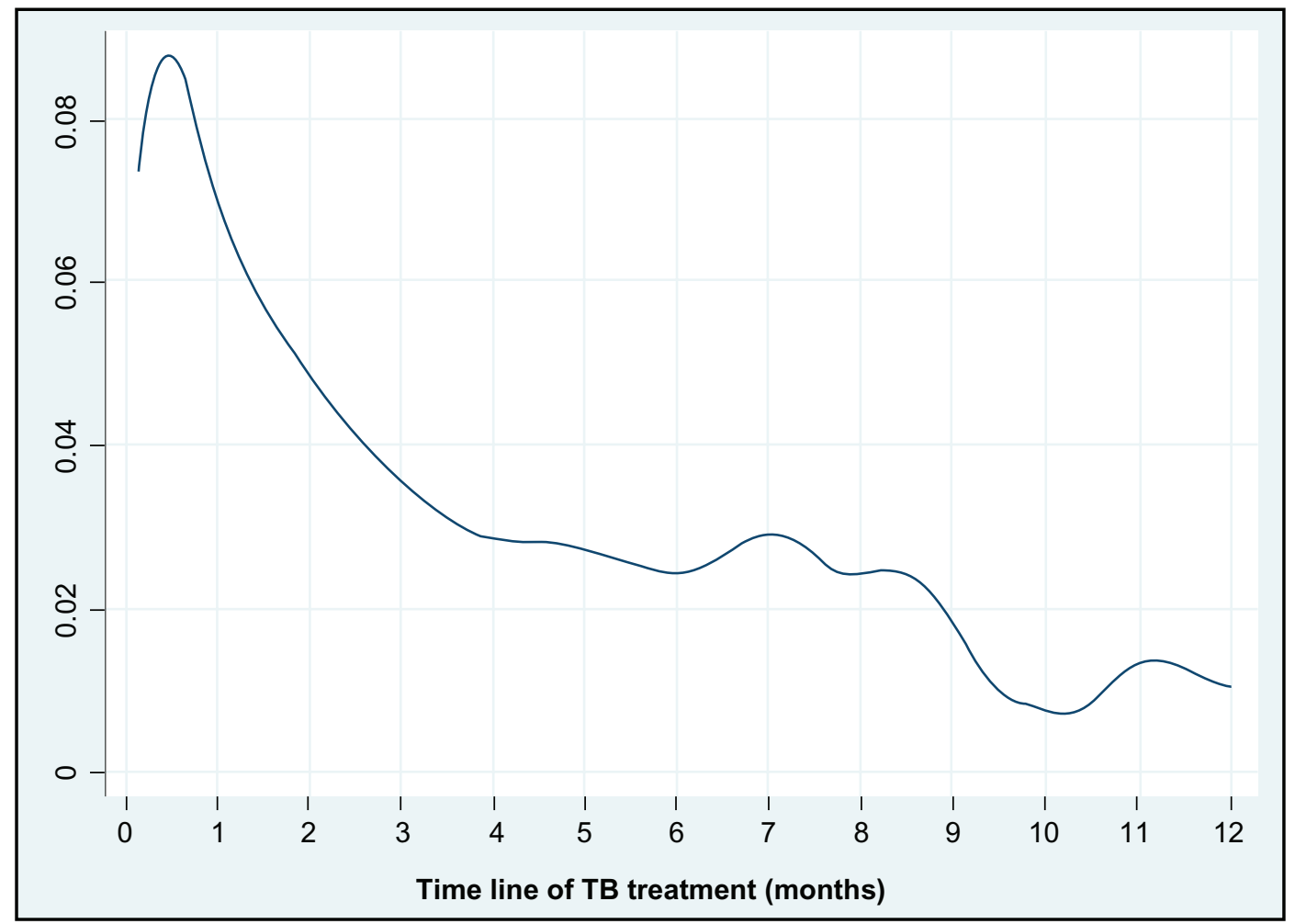

Figure 2 Smoothed hazard estimation of on-treatment TB deaths in Chiang Rai, Thailand (1997-2008). Y-axis is showing the probability of on-treatment TB death. X-aixs is showing the timeline of TB treatment.

Note: $\mathrm{N}=19174$, total death $=5009$.

analysis. The risk of death in the first month of TB treatment was found to be higher with advancing age (Figure 3 ).

Adjusted odds ratio were: aOR 17.1, CI 8.54-36.73 for age above 65 years; aOR 8.76, CI 4.15-18.45 in age 56-65 years group; aOR 4.60, CI 2.22-9.54 in age 46-55 years group; aOR 2.53, CI 1.23-5.21 in age 36-45 years group; and aOR 2.57, CI 1.26-5.24 in age 26-35 years group compared with the age 16-25 years group.

HIV-positive patients are more likely to die in the first month of TB treatment (aOR 3.24, CI 2.46-4.26) than HIV-negative patients. Thai citizens have a higher risk of TB death in the first month of treatment (aOR 2.26, CI 1.28-4.00) than Myanmar and Lao migrants. Married patients have less risk for TB death in the first month (aOR 0.61, CI 0.45-0.83) than single patients.

\section{Discussion}

\section{Time of highest on-treatment TB death}

Death caused by TB is preventable. Management and care can be modified at the time of highest risk for death. Many researches and reports have discussed TB mortality and factors associated with TB mortality. Usually, all TB deaths are summarized as one of the treatment outcomes at the end of
TB treatment. There is still a gap in the evidence needed to know the time of highest mortality.

Our observation of surveillance data over 12 years revealed that the highest proportion of TB deaths happened during the first month of TB treatment. The finding was persistent for more than a decade (Figures 1A-1C). The number of overall deaths became lower during the later 4 years 2005-2008. During 1997-2000, there was a lack of antiretroviral therapy (ART) for TB-HIV co-infected patients in Chiang Rai. After 2000, ART was provided by a national program, and access to ART was expanded with time. This may have led to an overall decline in the death rate in later years of observation. Nevertheless, the proportion of deaths was still the highest in the first month of TB treatment (Figures 1A, 1B, and 1C).

Harries et al identified in 1997 that $40 \%$ of TB deaths occurred in the first month of TB treatment in Malawi. ${ }^{9}$ It was an interesting report, with particular observation of the time of highest death during TB treatment. The percentage of death in the first month was very similar to our observation. The finding was based on 1-year data from the TB registry in 1997 from 38 hospitals in Malawi. It would be more informative to see the trend of TB deaths in subsequent years, because 
Table I Characteristics of TB patients included in the analysis

\begin{tabular}{|c|c|c|}
\hline Characteristics & $\begin{array}{l}\text { Patient died } \\
\text { in I month } \\
\mathrm{N}=534 \\
\mathrm{n}(\%)\end{array}$ & $\begin{array}{l}\text { Patient alive } \\
\text { at I month } \\
\mathrm{N}=5,092 \\
\mathrm{n}(\%)\end{array}$ \\
\hline \multicolumn{3}{|l|}{ Gender } \\
\hline Male & $362(67.8 \%)$ & 3332 (65.4\%) \\
\hline Female & $172(32.2 \%)$ & 1760 (34.6\%) \\
\hline \multicolumn{3}{|l|}{ Age (years) } \\
\hline Above 65 & 188 (35.2\%) & $756(14.8 \%)$ \\
\hline $56-65$ & 77 (I4.4\%) & 569 (II.2\%) \\
\hline $46-55$ & $83(15.5 \%)$ & 950 (18.7\%) \\
\hline $36-45$ & $84(15.7 \%)$ & 1214 (23.8\%) \\
\hline $26-35$ & $93(17.4 \%)$ & II 53 (22.6\%) \\
\hline $16-25$ & $9(1.7 \%)$ & 446 (8.8\%) \\
\hline Missing & - & $4(0.1 \%)$ \\
\hline Median (range) & $43(16-104)$ & 55 (16-95) \\
\hline \multicolumn{3}{|l|}{ Race } \\
\hline Thai & $46 I(86.3 \%)$ & 3732 (73.3\%) \\
\hline Hill tribe & 53 (9.9\%) & $846(16.6 \%)$ \\
\hline Non-Thai ${ }^{\mathrm{a}}$ & $20(3.7 \%)$ & $514(10.1 \%)$ \\
\hline \multicolumn{3}{|l|}{ Marital status } \\
\hline Married & $272(50.9 \%)$ & $3105(61 \%)$ \\
\hline Divorced & 38 (7.1\%) & 329 (6.5\%) \\
\hline Widowed & 105 (19.7\%) & $64 I(12.6 \%)$ \\
\hline Single & $70(13.1 \%)$ & $818(16.1 \%)$ \\
\hline Missing & 49 (9.2\%) & 199 (3.9\%) \\
\hline \multicolumn{3}{|l|}{ Education } \\
\hline Uneducated & 114 (21.3\%) & II 96 (23.5\%) \\
\hline Primary or lower & $193(36.1 \%)$ & I 877 (36.9\%) \\
\hline Secondary or higher & 37 (6.9\%) & 735 (14.4\%) \\
\hline Missing & $190(35.6 \%)$ & 1284 (25.2\%) \\
\hline \multicolumn{3}{|l|}{ Occupation } \\
\hline Household work & II 0 (20.7\%) & 494 (9.9\%) \\
\hline Unemployed & $36(6.7 \%)$ & $284(5.6 \%)$ \\
\hline Prisoner & $9(2.4 \%)$ & $76(1.7 \%)$ \\
\hline Business owner & $16(3 \%)$ & I83 (3.6\%) \\
\hline Government employee & $8(1.5 \%)$ & $105(2.1 \%)$ \\
\hline Farmer & $90(18 \%)$ & I 275 (26.8\%) \\
\hline Casual laborer & III (22.3\%) & 1816 (38.3\%) \\
\hline Other & $2(0.4 \%)$ & $126(2.5 \%)$ \\
\hline Missing & $152(28.5 \%)$ & $733(14.4 \%)$ \\
\hline \multicolumn{3}{|l|}{ Diabetes mellitus } \\
\hline Yes & 21 (3.9\%) & $215(4.2 \%)$ \\
\hline No & $338(63.3 \%)$ & 3884 (76.3\%) \\
\hline Missing & 175 (32.8\%) & 993 (19.5\%) \\
\hline \multicolumn{3}{|l|}{ Intravenous drug user } \\
\hline Yes & 17 (3.2\%) & 191 (3.8\%) \\
\hline No & $360(67.4 \%)$ & 3934 (77.3\%) \\
\hline Missing & 157 (29.4\%) & $967(19 \%)$ \\
\hline \multicolumn{3}{|l|}{ Prisoner } \\
\hline Yes & $8(1.5 \%)$ & $|2|(2.4 \%)$ \\
\hline No & $526(98.5 \%)$ & 4971 (97.6\%) \\
\hline \multicolumn{3}{|l|}{ BCG scar } \\
\hline Yes & 85 (I5.9\%) & $|42|$ (27.9\%) \\
\hline No & 175 (32.8\%) & 2159 (42.4\%) \\
\hline Missing & $274(51.3 \%)$ & 1512 (29.7\%) \\
\hline
\end{tabular}

(Continued)
Table I (Continued)

\begin{tabular}{|c|c|c|}
\hline Characteristics & $\begin{array}{l}\text { Patient died } \\
\text { in I month } \\
N=534 \\
n(\%)\end{array}$ & $\begin{array}{l}\text { Patient alive } \\
\text { at I month } \\
N=5,092 \\
n(\%)\end{array}$ \\
\hline \multicolumn{3}{|l|}{ Cough } \\
\hline No & III (20.8\%) & $94 \mathrm{I}(18.5 \%)$ \\
\hline$>14$ days & $15 \mid(28.3 \%)$ & $1973(38.7 \%)$ \\
\hline$\leq 14$ days & 106 (19.9\%) & II 29 (22.2\%) \\
\hline Missing & $166(31.1 \%)$ & 1049 (20.6\%) \\
\hline \multicolumn{3}{|l|}{ HIV status } \\
\hline Positive & 190 (35.6\%) & 1559 (30.6\%) \\
\hline Unknown & 62 (II.6\%) & $258(5.1 \%)$ \\
\hline Negative & $282(52.8 \%)$ & $3275(64.3 \%)$ \\
\hline \multicolumn{3}{|l|}{ Site of tuberculosis } \\
\hline Extrapulmonary TB & I 18 (22.1\%) & I I 37 (22.3\%) \\
\hline $\begin{array}{l}\text { Pulmonary TB } \\
\text { smear positive }\end{array}$ & 262 (49.1\%) & 2450 (48.1\%) \\
\hline $\begin{array}{l}\text { Pulmonary TB } \\
\text { smear unknown }\end{array}$ & 21 (3.9\%) & $120(2.4 \%)$ \\
\hline $\begin{array}{l}\text { Pulmonary TB } \\
\text { smear negative }\end{array}$ & 133 (24.9\%) & I 385 (27.2\%) \\
\hline \multicolumn{3}{|l|}{ Chest X-ray } \\
\hline Cavity & $53(8.7 \%)$ & $568(9.9 \%)$ \\
\hline Noncavity & $287(47 \%)$ & $2753(48.1 \%)$ \\
\hline Missing & $76(12.5 \%)$ & 634 (1I.1\%) \\
\hline \multicolumn{3}{|l|}{ Patient type } \\
\hline Relapse & $12(2.2 \%)$ & 99 (1.9\%) \\
\hline Failure & $5(0.9 \%)$ & $90(1.8 \%)$ \\
\hline TAD & 17 (3.2\%) & 198 (3.9\%) \\
\hline Other & 17 (3.2\%) & $270(5.3 \%)$ \\
\hline New & $483(90.4 \%)$ & 4435 (87.1\%) \\
\hline \multicolumn{3}{|l|}{ Sputum culture } \\
\hline Growth & $226(54.3 \%)$ & $23 \mid 4(58.5 \%)$ \\
\hline No growth & $80(19.2 \%)$ & 764 (19.3\%) \\
\hline Missing & $110(26.4 \%)$ & $877(22.2 \%)$ \\
\hline \multicolumn{3}{|l|}{ MDR TB } \\
\hline Yes & $4(1.8 \%)$ & $42(1.8 \%)$ \\
\hline No & 197 (87.2\%) & 1947 (84.1\%) \\
\hline Missing & $25(11.1 \%)$ & $325(14 \%)$ \\
\hline \multicolumn{3}{|l|}{ Drug resistance } \\
\hline One or more ${ }^{\mathrm{b}}$ & $33(14.6 \%)$ & $360(15.6 \%)$ \\
\hline None & 168 (74.3\%) & $1629(70.4 \%)$ \\
\hline Missing & 25 (II.1\%) & 325 (14\%) \\
\hline
\end{tabular}

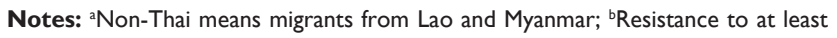
one or more anti-TB drug: isoniazid, rifampicin, ethambutol, and streptomycin.

Data source: TB surveillance database collaboration between Chiang Rai Provincial Health Office, Thailand, and Research Institute of Tuberculosis, Japan.

Abbreviations: MDR-TB, multidrug-resistant tuberculosis; TAD, treatment after default.

there were many changes, such as HIV prevalence, TB control activity, and policy. In our report, the proportion of TB deaths in the course of treatment can be seen serially for 12 years.

The same author in 2001 reported $40 \%-45 \%$ of all TB deaths in the first month of TB treatment regardless of daily or intermittent regimens in Malawi. ${ }^{10}$ All these studies were at the same site, Malawi, which is a TB and HIV endemic area in Africa. Sub-Saharan Africa has a very high HIV prevalence 
Table 2 Factors associated with TB patients who died in the first month of TB treatment in Chiang Rai, Thailand (2005-2008)

\begin{tabular}{|c|c|c|c|}
\hline Characteristics & $\begin{array}{l}\text { Patient died } \\
\mathrm{n} / \mathrm{N}(\%)\end{array}$ & $\begin{array}{l}\text { Bivariate OR } \\
(95 \% \mathrm{Cl})\end{array}$ & $\begin{array}{l}\text { Adjusted } \\
\text { OR }(95 \% \mathrm{Cl})\end{array}$ \\
\hline \multicolumn{4}{|l|}{ Gender } \\
\hline Male & $362 / 3694$ (9.8\%) & I.II (0.92-I.34) & $1.03(0.84-1.26)$ \\
\hline Female & I72/I932 (8.9\%) & Referent & Referent \\
\hline \multicolumn{4}{|l|}{ Age (years) } \\
\hline$>65$ & 188/944 (19.9\%) & $12.32(6.25-24.30)^{c}$ & I7.7| (8.54-36.73) \\
\hline $56-65$ & $77 / 646$ (11.9\%) & $6.71(3.33-13.52)^{c}$ & $8.76(4.15-18.45)^{c}$ \\
\hline $46-55$ & $83 / 1033(8 \%)$ & $4.33(2.16-8.69)^{c}$ & $4.60(2.22-9.54)^{c}$ \\
\hline $36-45$ & $84 / 1298(6.5 \%)$ & $3.43(1.7 I-6.88)^{c}$ & $2.53(1.23-5.21)^{c}$ \\
\hline $26-35$ & $93 / 1246(7.5 \%)$ & $4.00(2.00-7.99)^{c}$ & $2.57(1.26-5.24)^{c}$ \\
\hline $16-25$ & $9 / 455$ (2\%) & Referent & Referent \\
\hline \multicolumn{4}{|l|}{ Race } \\
\hline Thai & $461 / 4193$ (II\%) & $3.17(2.0 \mathrm{I}-5.0 \mathrm{I})^{\mathrm{c}}$ & $2.26(1.28-4.00)^{c}$ \\
\hline Hill tribe & $53 / 899(5.9 \%)$ & I.6I (0.95-2.72) & $1.76(0.94-3.30)$ \\
\hline Non-Thai ${ }^{\mathrm{a}}$ & $20 / 534$ (3.7\%) & Referent & Referent \\
\hline \multicolumn{4}{|l|}{ Marital status } \\
\hline Married & $272 / 3377$ (8.1\%) & I.02 (0.78-I.35) & $0.6 \mathrm{I}(0.45-0.83)^{\mathrm{c}}$ \\
\hline Divorced & $38 / 367(10.4 \%)$ & $1.35(0.89-2.04)$ & $0.80(0.52-1.23)$ \\
\hline Widowed & $105 / 746(14.1 \%)$ & $1.91(1.39-2.64)^{c}$ & $0.71(0.49-1.02)$ \\
\hline Single & $70 / 888(7.9 \%)$ & Referent & Referent \\
\hline \multicolumn{4}{|l|}{ Education } \\
\hline Uneducated & $1 \mid 4 / 1310$ (8.7\%) & $1.89(1.29-2.77)^{c}$ & NS \\
\hline Primary or lower & $193 / 2070$ (9.3\%) & $2.04(1.42-2.93)^{c}$ & \\
\hline Secondary or higher & $37 / 772$ (4.8\%) & Referent & \\
\hline \multicolumn{4}{|l|}{ Occupation } \\
\hline Household work & $110 / 604$ (18.2\%) & $3.64(2.75-4.83)^{c}$ & NS \\
\hline Unemployed & $36 / 320$ (II.3\%) & $2.07(1.40-3.08)^{c}$ & \\
\hline Prisoner & $9 / 85(10.6 \%)$ & $1.94(0.95-3.97)$ & \\
\hline Business owner & $16 / 199(8 \%)$ & I.43 (0.83-2.47) & \\
\hline Government employee & $8 / 113$ (7.1\%) & $1.25(0.59-2.62)$ & \\
\hline Farmer & $90 / 1365(6.6 \%)$ & $1.15(0.87-1.54)$ & \\
\hline Other & $2 / 128(1.6 \%)$ & $0.26(0.06-1.06)$ & \\
\hline Casual laborer & I I I/I 927 (5.8\%) & Referent & \\
\hline \multicolumn{4}{|l|}{ Diabetes mellitus } \\
\hline Yes & $21 / 236(8.9 \%)$ & I.I2 (0.7I-I.78) & NS \\
\hline No & $338 / 4222(8 \%)$ & Referent & \\
\hline \multicolumn{4}{|l|}{ Intravenous drug users } \\
\hline Yes & I7/208 (8.2\%) & $0.97(0.59-1.62)$ & NS \\
\hline No & $360 / 4294(8.4 \%)$ & Referent & \\
\hline \multicolumn{4}{|l|}{ Prisoner } \\
\hline Yes & $8 / 129$ (6.2\%) & $0.62(0.30-1.29)$ & NS \\
\hline No & $526 / 5497(9.6 \%)$ & Referent & \\
\hline \multicolumn{4}{|l|}{ BCG scar } \\
\hline Yes & $85 / 1506(5.6 \%)$ & $0.74(0.56-0.96)^{c}$ & NS \\
\hline No & I75/2334 (7.5\%) & Referent & \\
\hline \multicolumn{4}{|l|}{ Cough } \\
\hline No & III/I052 (I0.6\%) & $1.26(0.95-1.66)$ & NS \\
\hline$>14$ days & $15|/ 2| 24$ (7.1\%) & $0.82(0.63-1.06)$ & \\
\hline$\leq 14$ days & 106/I235 (8.6\%) & Referent & \\
\hline \multicolumn{4}{|l|}{ HIV status } \\
\hline Positive & $190 / 1749$ (10.9\%) & $1.42(1.17-1.72)^{c}$ & $3.24(2.46-4.26)^{c}$ \\
\hline Unknown & $62 / 320(19.4 \%)$ & $2.79(2.06-3.78)^{\mathrm{c}}$ & $1.77(1.28-2.46)^{c}$ \\
\hline Negative & $282 / 3557(7.9 \%)$ & Referent & Referent \\
\hline \multicolumn{4}{|l|}{ Site of tuberculosis } \\
\hline Extra-pulmonary TB & I I8/I255 (9.4\%) & $0.99(0.80-1.22)$ & NS \\
\hline Pulmonary TB & $416 / 437 \mid(9.5 \%)$ & Referent & \\
\hline
\end{tabular}


Table 2 (Continued)

\begin{tabular}{|c|c|c|c|}
\hline Characteristics & $\begin{array}{l}\text { Patient died } \\
\text { n/N (\%) }\end{array}$ & $\begin{array}{l}\text { Bivariate OR } \\
(95 \% \mathrm{Cl})\end{array}$ & $\begin{array}{l}\text { Adjusted } \\
\text { OR }(95 \% \mathrm{Cl})\end{array}$ \\
\hline \multicolumn{4}{|l|}{ Chest X-ray } \\
\hline Cavity & $53 / 621$ (8.5\%) & $0.90(0.66-1.22)$ & NS \\
\hline Non-cavity & $287 / 3040$ (9.4\%) & Referent & \\
\hline \multicolumn{4}{|l|}{ Patient type } \\
\hline Relapse & $|2 /|||(\mid 0.8 \%)$ & I.II (0.6I-2.04) & NS \\
\hline Failure & $5 / 95(5.3 \%)$ & $0.5 \mathrm{I}(0.2 \mathrm{I}-\mathrm{I} .26)$ & \\
\hline TAD & $17 / 2 \mid 5$ (7.9\%) & $0.79(0.48-1.3 \mid)$ & \\
\hline Other & I7/287 (5.9\%) & $0.58(0.35-0.95)^{c}$ & \\
\hline New & $483 / 4918$ (9.8\%) & Referent & \\
\hline \multicolumn{4}{|l|}{ Sputum culture } \\
\hline Growth & $226 / 2540$ (8.9\%) & $0.93(0.7|-| .22)$ & NS \\
\hline No growth & $80 / 844$ (9.5\%) & Referent & \\
\hline \multicolumn{4}{|l|}{ MDR TB } \\
\hline Yes & $4 / 46$ (8.7\%) & $0.94(0.33-2.65)$ & NS \\
\hline No & $197 / 2 \mid 44$ (9.2\%) & Referent & \\
\hline \multicolumn{4}{|l|}{ Drug resistance } \\
\hline One or more ${ }^{b}$ & $33 / 393$ (8.4\%) & $0.89(0.6-|.3|)$ & NS \\
\hline None & I 68/I 797 (9.3\%) & Referent & \\
\hline
\end{tabular}

Notes: ${ }^{\mathrm{a}}$ Non-Thai means migrants from Lao and Myanmar; ${ }^{\mathrm{b}}$ Resistance to at least one or more anti-TB drug: isoniazid, rifampicin, ethambutol, and streptomycin; ${ }^{\mathrm{c} P}<0.05$. Data source: TB surveillance database collaboration between Chiang Rai Provincial Health Office, Thailand, and Research Institute of Tuberculosis, Japan.

Abbreviations: $\mathrm{Cl}$, confidence interval; MDR-TB, multidrug-resistant tuberculosis; NS, not significant; OR, odds ratio; TAD, treatment after default.

that considerably fuels the TB death rates. However, other WHO regions, such as Southeast Asia and Europe, currently have a different HIV prevalence and TB epidemiology from those of Sub-Saharan Africa.

Our observation in Northern Thailand has identified the first month of TB treatment as the time of highest risk for TB death. The same pattern has continued consecutively for more than a decade. Therefore, it would be practical to launch interventions focusing on the first month of TB treatment in order to cut mortality. Our finding is expected to be applicable in many countries with similar TB epidemiology and problems globally.

\section{Factors related to death in first month of TB treatment}

Factors particularly associated with TB death in the first month of treatment were investigated to identify at-risk groups of patients. Clinical, laboratory, and sociodemo-

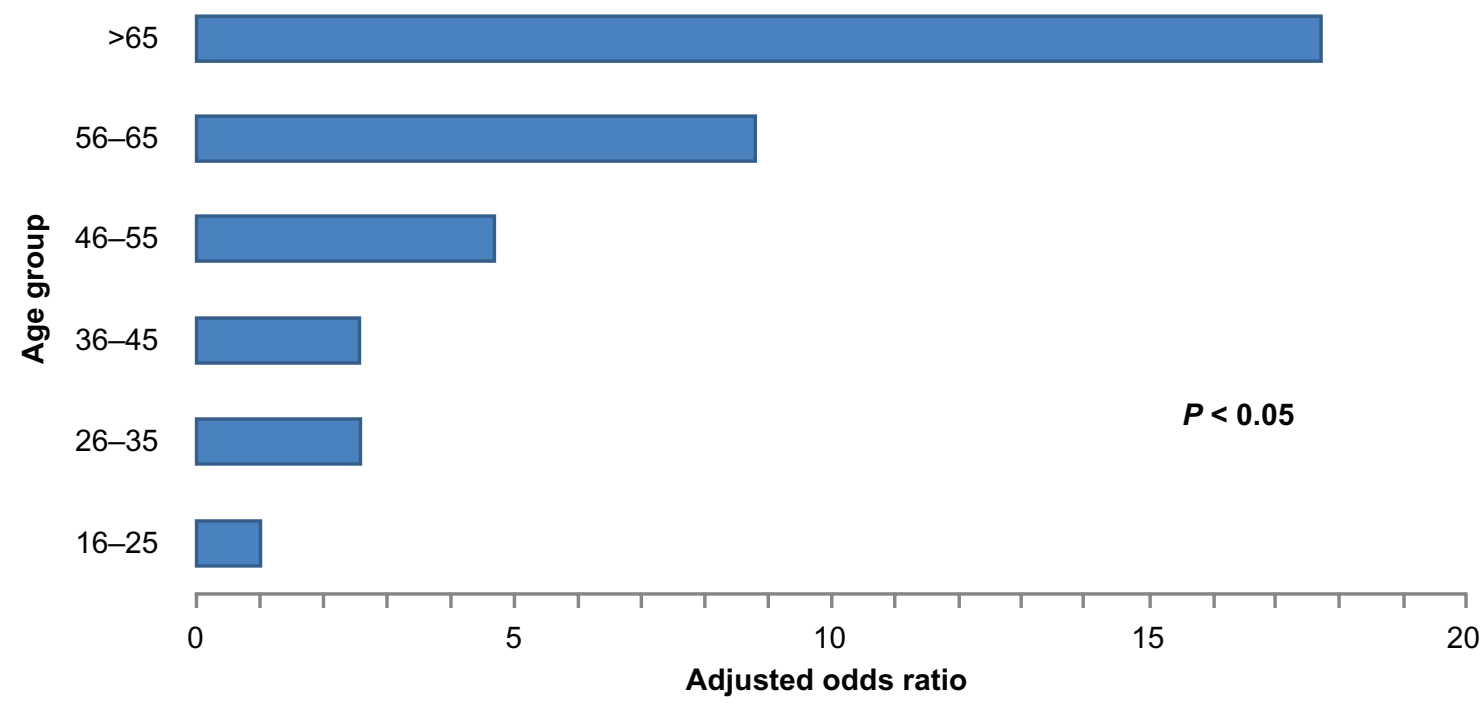

Figure 3 Risk of TB death during the first month of TB treatment in different age groups in Chiang Rai, Thailand (2005-2008). 
graphic factors were analyzed. We found that advancing age, HIV infection, and being Thai were strongly associated with death in the first month of TB treatment.

Previously, studies across the world have shown the factors associated with TB mortality. Mostly, factors associated with treatment outcome death were reported. A few studies pointed out the risk factors for early death. Even before the HIV pandemic, early TB death and an association with older patients were stated in England and Wales. ${ }^{11}$ A low body mass index less than $17.0 \mathrm{~kg} / \mathrm{m}^{2}$ was also revealed as a risk factor for early mortality. ${ }^{12}$ A later study in Africa reported a higher death rate in HIV-positive TB patients. ${ }^{13}$

Our result has shown the higher risk of early TB death with advancing age. The death rate in the first month specified by age groups increased with advancing age (Table 1). AOR increased progressively with advancing age (Figure 3 ). TB patients aged above 65 years were found to have the highest risk compared with other adult age groups (aOR 17.71, 95\% CI 8.54-36.73).

Previous studies in various regions of the world reported high risk for elderly TB patients, but the risk was not specified for death in the first month. ${ }^{7,11,14-19}$ Recently, analysis of TB surveillance data from 15 European Union (EU) countries during 2002-2004 reported that advancing age and resistance to isoniazid and rifampicin were the strongest risks of TB death. ${ }^{19}$ Therefore, our finding agreed with existing evidence for those at high-risk of TB death. Moreover, we specified the most likely time of death for these high-risk patients. However, the WHO definition of TB death covered death from any cause during TB treatment. Elderly TB patients might have comorbid diseases. Thus, it is difficult to claim $\mathrm{TB}$ as the sole contributor of death.

Currently, TB and HIV are two of the deadliest chronic infections globally. ${ }^{20}$ In our study cohort from 2005-2008, $31 \%$ of all the TB patients were HIV positive. Among the deaths of patients during the first month, 35.6\% were HIV positive (Table 1). HIV-infected TB patients have significant risk for death in the first month of TB treatment. The aOR was 3.24 (2.46-4.26). Unidentified status of HIV infection was also a risk factor for earlier TB death.

Previous studies have stated that HIV infection is an important risk factor for TB mortality. ${ }^{21-23}$ Early deaths of TB-HIV co-infected patients were more likely caused by TB rather than other opportunistic infections. ${ }^{21} \mathrm{CD} 4$ cell depletion is a possible explanation for the higher death rates in HIV-positive TB patients. Consequently, timely ART would be an important factor. Moreover, adverse effects are common because of interaction between antiretroviral drugs and anti-TB drugs.
Historically, TB was said to be a disease of poor people. The risk of TB death and its time of occurrence could be related to socioeconomic factors. However, in our analysis, occupation and educational status of the patients were not significant after adjustment with a multilogistic regression model. Final analysis showed that being a Thai citizen is a significant risk factor. A similar observation was reported in a European study and was explained as the healthy migrant effect. ${ }^{19}$ Bacteriological factors related to causal organism like culture positivity, drug resistance, and multidrugresistant TB (MDR-TB) were not significant factors in the current study. However, previous studies in Thailand and Europe reported that MDR-TB was a significant risk for overall TB death. ${ }^{7,19}$ The different finding could be due to a different time point of analysis and low level of MDR-TB prevalence in Chiang Rai.

More complete clinical data should be analyzed to identify risk groups who could die earlier. Recently, a study of 311 hospitalized TB patients in Brazil reported high mortality rates among hospitalized TB patients in a highly HIV prevalent setting. Respiratory failure requiring mechanical ventilation, smear negative sputum, and consolidation in chest $\mathrm{X}$-ray are identified as predictors of in-hospital death. ${ }^{24} \mathrm{It}$ was a limitation of our study that we could not explore much about the factors related to anti-TB drugs, which were in fact a constant exposure in the study cohort. Most of our study cohort (more than 85\%) comprised new cases treated by a WHO category I regimen ${ }^{8}$ (Table 1). Daphne and colleagues have reported that the occurrence of serious side effects of anti-TB drugs were more common in patients aged over 65 years and in HIV-positive patients. ${ }^{25}$ In the past, one of the inclusion criteria of clinical trials was patients' age to be between 15 and 65 years. ${ }^{26}$ Therefore, it is hard to know about adverse events in TB patients aged above 65 years. Further studies of decades-old TB regimens in elderly patients would be necessary.

The time of highest TB deaths was found to be the earlier period in TB treatment. Delayed diagnosis and late presentation may be associated with early TB death. However, a study in Vietnam reported that diagnostic delay was not associated with TB treatment outcome mortality. ${ }^{18}$ Prospective studies beyond the scope of surveillance, based on contemporary evidence, should be assembled in future.

\section{Suggestions and proposed strategies}

Our analysis showed that elderly patients and HIV coinfected patients were the people at higher risk for early TB death. Elderly patients can have other allied illnesses, 
such as malignancy, other respiratory infections, and underlying liver diseases, which may lead to earlier TB death. A hospital-based prospective study focusing on the elderly and further analysis of more complete information on cause of death is necessary. A careful start to the administration of anti-TB drugs with a body weight-based adjusted dose, complete baseline clinical and laboratory investigations, and more frequent follow-ups are necessary. A TB hospital providing meticulous care of high-risk patients at the initiation of TB treatment in such an endemic area may be fruitful to save these risk groups.

To prevent early TB death in TB-HIV co-infected patients, ART coverage and access to ART is crucial in all settings, as the decline of overall death rate in later years of our observation has shown (Figure 1C). During the 12 years of the current study period, up to 2008, Thailand national guidelines recommended deferring ART in TB-HIV coinfection until 2 months after initiation of TB treatment in cases with CD4 count more than 200 cells/ul. ${ }^{27,28} \mathrm{New}$ national guidelines for Thailand in 2010 changed the recommendation to start ART earlier but still, to defer ART if CD4 count is above 350 cells/ul. ${ }^{29}$ Current international guidelines recommend starting ART in HIV infected persons with active TB disease irrespective of their CD4 count. ${ }^{30,31}$ This strategy would help to reduce the early TB deaths in TB-HIV patients.

In conclusion, current study findings are useful clues for launching realistic prevention strategies against TB deaths in many countries. Across the course of TB treatment, the first month sees the highest number of TB deaths. During that first month, elderly patients and HIV-infected patients are at significantly high risk of death. It is expected that prioritizing interventions focused on high-risk times and high-risk patients will diminish mortality related to TB globally.

\section{Acknowledgments}

All the staffs of the TB clinics at 17 hospitals in Chiang Rai province and the staffs of TB/HIV Research Foundation are acknowledged for their help and support. Thailand TB Active Surveillance Network (TB-Net) is acknowledged for collaboration of the TB surveillance system from 2005 to 2008. Thaworn Lorga, Boromrajonani College of Nursing, Lampang, Thailand is acknowledged for his important suggestions

\section{Disclosure}

No conflicts of interest were declared in relation to this paper.

\section{References}

1. Centers for Disease Control and Prevention. Fact sheet: A global perspective on tuberculosis. 2009. Available from: http://www.cdc.gov/tb/ events/WorldTBDay/resources_global.htm. Accessed Dec 18, 2010.

2. [WHO] World Health Organization. WHO report 2009: Global tuberculosis control. Available from: http://www.who.int/tb/publications/ global_report/2009/key_points/en/index.html. Accessed Dec 18, 2010.

3. Centers for Disease Control and Prevention. Reported tuberculosis in the United States, 2008. Available from: http://www.cdc.gov/tb/statistics/ reports/2008/default.htm. Accessed Dec 18, 2010.

4. [WHO] World Health Organization. TB in South-East Asia: Epidemiology of TB in the Region. Available from: http://www searo.who.int/en/Section10/Section2097/Section2100_10639.htm. htm. Accessed Dec 18, 2010.

5. [WHO] World Health Organization. TB data: Data collected from TB control programmes and estimates generated by WHO, treatment outcomes, new smear-positive cases, 1995-2007. Available from: http:// www.who.int/tb/country/data/download/en/index.html. Dec 18, 2010.

6. Moolphate S. TB HIV situation in Chaing Rai province. Report presented at: The 14th TB HIV Annual Meeting; 2010 January 13; Chiang Rai, Thailand Chiang Rai.

7. Amnuaiphon W, Anuwatnonthakate A, Nuyongphak P, et al. Factors associated with death among HIV-uninfected TB patients in Thailand, 2004-2006. Trop Med Int Health. 2009;2014(2011):1338-2046.

8. [WHO] World Health Organization. Treatment of tuberculosis: guidelines for national programmes. 4th ed. WHO. 2009:420

9. Harries AD, Hargreaves NJ, Gausi F, Kwanjana JH, Salaniponi FM. High early death rate in tuberculosis patients in Malawi. Int J Tuberc Lung Dis. 2001;5(11):1000-1005.

10. Harries AD, Gausi FK, Kwanjana JH, Nyirenda TE, Salaniponi FM. Is oral intermittent initial phase anti-tuberculosis treatment associated with higher mortality in high HIV-prevalent areas in sub-Saharan Africa? Int J Tuberc Lung Dis. 2001;5(5):483-485.

11. Humphries MJ, Byfield SP, Darbyshire JH, et al. Deaths occurring in newly notified patients with pulmonary tuberculosis in England and Wales. Br J Dis Chest. 1984;78:149-158.

12. Zachariah R, Spielmann MP, Harries AD, Salaniponi FM. Moderate to severe malnutrition in patients with tuberculosis is a risk factor associated with early death. Trans R Soc Trop Med Hyg. 2002;96(3):291-294.

13. Kang'ombe C, Harries AD, Banda H, et al. High mortality rates in tuberculosis patients in Zomba Hospital, Malawi, during 32 months of follow-up. Trans R Soc Trop Med Hyg. 2000;94(3):305-309.

14. Shen X, Deriemer K, Yuan Z, et al. Deaths among tuberculosis cases in Shanghai, China: who is at risk? BMC Infect Dis. 2009;9:95.

15. Facanha MC. Evolution of tuberculosis-related mortality in Fortaleza, Brazil from 1980 to 2001. J Bras Pneumol. 2006;32(6):553-558.

16. Najera-Ortiz J, Sanchez-Perez H, Ochoa-Diaz H, Arana-Cedeno M, Lezama MS, Mateo MM. Demographic, health services and socioeconomic factors associated with pulmonary tuberculosis mortality in Los Altos Region of Chiapas, Mexico. Int J Epidemiol. 2008;37(4): 786-795.

17. Kolappan C, Subramani R, Kumaraswami V, Santha T, Narayanan PR. Excess mortality and risk factors for mortality among a cohort of TB patients from rural south India. Int J Tuberc Lung Dis. 2008;12(1): $81-86$.

18. Vree M, Huong N, Duong B, et al. High mortality during tuberculosis treatment does not indicate long diagnostic delays in Vietnam: a cohort study. BMC Public Health. 2007;7(1):210.

19. Lefebvre N, Falzon D. Risk factors for death among tuberculosis cases: analysis of European surveillance data. Eur Resp J. 2008;31(6): $1256-1260$.

20. Harrington M. From HIV to tuberculosis and back again: a tale of activism in 2 pandemics. Clin Infect Dis. 2010;50(S3):S260-S266.

21. Churchyard GJ, Kleinschmidt I, Corbett EL, Murray J, Smit J, de Cock KM. Factors associated with an increased case-fatality rate in HIV-infected and non-infected South African gold miners with pulmonary tuberculosis. Int J Tuberc Lung Dis. 2000;4(8):705-712. 
22. Mugusi F, Mehta S, Villamor E, et al. Factors associated with mortality in HIV-infected and uninfected patients with pulmonary tuberculosis. BMC Public Health. 2009;9(1):409.

23. Murray J, Sonnenberg P, Shearer SC, Godfrey-Faussett P. Human immunodeficiency virus and the outcome of treatment for new and recurrent pulmonary tuberculosis in African patients. Am J Respir Crit Care Med. 1999;159(3):733-740.

24. Silva DR, Menegotto DM, Schulz LF, Gazzana MB, Dalcin Pde T. Factors associated with mortality in hospitalized patients with newly diagnosed tuberculosis. Lung. 2010;188(1):33-41.

25. Yee D, Valiquette C, Pelletier M, Parisien I, Rocher I, Menzies D. Incidence of serious side effects from first-line antituberculosis drugs among patients treated for active tuberculosis. Am J Respir Crit Care Med. 2003;167(11):1472-1477.

26. Jindani A, Nunn AJ, Enarson DA. Two 8-month regimens of chemotherapy for treatment of newly diagnosed pulmonary tuberculosis: international multicentre randomised trial. Lancet. 2004;364(9441): 1244-1251.
27. Sungkanuparph S, Anekthananon T, Hiransuthikul N, et al. Guidelines for antiretroviral therapy in HIV-1 infected adults and adolescents: the recommendations of the Thai AIDS Society (TAS) 2008. J Med Assoc Thai. 2008;91(12):1925-1935.

28. Department of Disease Control MoPH. Thailand National Antiretroviral Treatment Guideline (2006/2007).

29. Sungkanuparpha S, Techasathit WT, Utaipiboonc C, et al. Thai national guidelines for antiretroviral therapy in HIV-1 infected adults and adolescents 2010. Asian Biomed. 2010;4(4):515-528.

30. [WHO] World Health Organization. Antiretroviral therapy for HIV infection in adults and adolescents. Available from: http://www.who. int/hiv/pub/arv/adult2010/en/index.html. Accessed Dec 18, 2010.

31. Thompson MA, Aberg JA, Cahn P, et al. Antiretroviral treatment of adult HIV infection: 2010 Recommendations of the International AIDS Society-USA Panel. JAMA. 2010;304(3):321-333.

\section{Publish your work in this journal}

The International Journal of General Medicine is an international, peer-reviewed open-access journal that focuses on general and internal medicine, pathogenesis, epidemiology, diagnosis, monitoring and treatment protocols. The journal is characterized by the rapid reporting of reviews, original research and clinical studies across all disease areas.
A key focus is the elucidation of disease processes and management protocols resulting in improved outcomes for the patient. The manuscript management system is completely online and includes a very quick and fair peer-review system. Visit http://www.dovepress.com/ testimonials.php to read real quotes from published authors. 